\title{
Patterns of cervical cancer brachytherapy in India: results of an online survey supported by the Indian Brachytherapy Society
}

\author{
Abhishek Chatterjee, MD!, Surbhi Grover, MD, MPH², Lavanya Gurram, MD!, Prof. Supriya Sastri, MD!, \\ Prof. Umesh Mahantshetty, MD' \\ 'Department of Radiation Oncology, Tata Memorial Hospital, Homi Bhabha National Institute (HBNI) Mumbai, India, ${ }^{2}$ Department of \\ Radiation Oncology, University of Pennsylvania, Pennsylvania, PA, USA
}

\begin{abstract}
Purpose: Cervical cancer is the most common gynecological cancer in India. Uniform protocol-based treatment is important for achieving optimal outcomes. We undertook a survey to investigate patterns of care with special regard to patterns of care in cervical cancer brachytherapy in India.

Material and methods: A 17-question online survey was sent to radiation oncologists across India. Respondents were required to have a minimum of 1-year experience. One response per center was accepted and deemed as representative.

Results: Out of 116 centers, 59 responses were generated. Two-thirds (66.1\%) were from academic centers and the majority (96.6\%) used high-dose-rate (HDR) brachytherapy. The centers treated an average of 255 patients per year (median 161 patients, IQR 76-355). The majority were locally advanced cancers (FIGO 2009 stage II-IV 87.5\%). External beam radiotherapy (EBRT) schedules were fairly consistent, administering doses of 45-50 Gy over 5 weeks. Brachytherapy was performed towards EBRT completion by 37/59 (62\%) and 43/59 (74.3\%) centers used a schedule of 7 Gy $\times 4$ fractions (HDR). Brachytherapy was commonly performed under anesthesia (spinal/general: $44 \%$ each) with ultrasound (USG) guidance (29\%). Computed tomography (CT) imaging (65\%) and orthogonal X-rays (35\%) represented the most common imaging for planning, while point A prescription (66\%) or GEC-ESTRO based parameters (35\%) with manual/geometric methods represented the most common methodology for dose volume prescription and optimization. Overall treatment time (OTT) reported was within $49-56$ days in $50 \%$. Complex implants (IC + IS) were performed for more than $30 \%$ of cases by 3 centers.

Conclusions: Our survey suggested a fairly uniform treatment paradigm for cervical cancer brachytherapy, with a progressive shift from 2D to 3D image-based parameters for planning, with persistence of point $\mathrm{A}$ based prescription. Further efforts are needed to augment and ease this transition.

Key words: cervical cancer, India, brachytherapy, patterns of care.

\section{Purpose}

Cervical cancer remains a major global healthcare problem, with 569847 new cases and 311365 deaths occurring worldwide each year [1]. The major burden of this mortality is borne by the lesser-developed regions of the world. In India, it is a source of major morbidity and mortality, with 96922 new cases occurring annually, and 60078 women succumbing to this disease. A majority of patients present to the clinic with advanced stages of disease [2].

Aggressive multi-modality therapy can lead to encouraging outcomes in these patients [3]. These outcomes are typically achieved in the context of timely, multidisciplinary care. In locally advanced cervical cancer (LACC), radical radio-chemotherapy with external beam radiotherapy (EBRT), concomitant radio-sensitizing chemotherapy and intra-cavitary brachytherapy (ICBT) with adequate doses and an overall treatment time of 7-8 weeks is vital for disease outcome and toxicities. However, depending on the resource availability, logistics and socio-economic issues especially in low and middle income countries (LMICs), the prevalent practices are heterogeneous and seldom reported. We conducted this online survey with an aim to investigate and understand the patterns of care of cervical cancer brachytherapy in India
Address for correspondence: Prof. Umesh Mahantshetty, MD, Department of Radiation Oncology, Tata Memorial Hospital, Mumbai-400012, phone: +91(22)-24177000, ext. 7168,

e-mail: drumeshm@gmail.com
Received: 30.08 .2019

Accepted: 06.11.2019

Published: 23.12.2019 
in terms of scheduling, protocol, imaging used, dose volume prescription and usage of and aspirations regarding future implementation of image-guided brachytherapy (IGBT). The results of the survey form the basis of this report. The survey was conducted under the aegis of the Indian Brachytherapy Society (IBS), a non-profit all-India organization which provides the primary impetus towards improving brachytherapy practice and knowledge in the country [4] and has recently published comprehensive guidelines related to the management of carcinoma with emphasis on ICBT [5].

\section{Material and methods}

The survey was exempt from Institutional Review Board submission. A 17-question online survey was sent via electronic mail to radiation oncologists involved in the treatment of gynecological malignancies at 116 centers in India. The questionnaire included the nature of practice (government vs. private, academic vs. non-academic), caseload of cervical cancers handled every year, distribution of cases, timing of ICBT relative to EBRT, dose fractionation schedules used, usage and type of anesthesia, type of applicators used and type of implants performed, imaging used intra-operatively during insertion and for planning, method of dose prescription and dose constraints used. The responders were also asked regarding the overall treatment times typically achieved during treatment and also as to their desire for implementing 3-dimensional image-based brachytherapy in the near future (see Table 1). Respondents were required to have at least 1-year post-residency experience to be eligible. One response per center was deemed as representative of clinical practice at the center. In the case of multiple responses, the responder with the greater experience was chosen. Data were collected from the online survey responses and analyzed using SPSS Version 22 (IBM Corp. Armonk, NY, USA).

Descriptive statistics were used to analyze the responses in terms of frequencies and percentages. For looking at factors determining the use of IGBT the study team first selected certain factors deemed relevant in terms of prognostic significance (experience, type of setup, caseload and percentage of advanced cases seen in clinical practice). All values were dichotomized at the median except experience, which was divided into 5-year intervals to facilitate analysis (experience less than five years and experience less than ten years). Associations with categorical variables (such as experience, type of setup) were tested by the chi square test, while those with continuous variables (such as caseload, percentage of advanced cases seen) were tested by means of the $t$-test.

\section{Results}

Between January and June 2017, 116 respondents were contacted over e-mail and postal mail. Fifty-nine respondents replied to the survey mail and contributed data for the analysis. The overall response rate was 51\% (59/116). Fifty-nine percent $(35 / 59)$ of respondents were from academic centers (including government medical colleges, private medical colleges with radiotherapy departments with residency courses, and regional and state cancer centers funded by the government), and the remaining $34 \%(24 / 59)$ were from private oncology centers. Eightyeight percent of respondents $(51 / 59)$ had more than five years of experience in treating gynecological cancers, and $53 \%$ of respondents $(30 / 59)$ reported more than ten years of experience.

The average number of cases of cervical cancer treated every year was 255 (median: 161 cases, IQR 76-355). The pattern of case presentation was typically dominated by advanced stages (FIGO 2009 stage IB2-IVA), which constituted $87 \%$ of the cases seen by respondents in their clinical practice. All respondents used a combination of EBRT and ICBT to treat cervical cancer. EBRT practice was fairly constant, with all centers administering doses $\geq 45$ Gy at 1.8-2 Gy per fraction. Sixty-two percent of centers (37/59) performed ICBT after conclusion of EBRT. The usage of midline blocks (MLB) was reported by $20 \%$ of centers $(12 / 60)$. The most common dose fractionation schedule used was $7 \mathrm{~Gy}$ per fraction, once weekly for a total of 3-4 applications (74\%, 43/59 centers). High-dose-rate (HDR) brachytherapy was the predominant mode of administration of ICBT, with $97 \%(57 / 59)$ of centers reporting its usage. The majority of centers were able to complete treatment within $49-56$ days (44\%, 26/59 centers), with $10 \%$ of centers (6/59 centers) exceeding 56 days.

Centers reported multiple forms of anesthesia usage in the same institute. These included general anesthesia $(44 \%, 26 / 59$ centers), spinal anesthesia $(44 \%, 26 / 59$ centers), and regional anesthesia ( $27 \%, 10 / 59$ centers).

Ultrasound (USG) guidance was used for optimizing applicator insertion and placement by $29 \%$ of respondents (16/59 centers). Computed tomography (CT) scan was used to check the correctness of applicator placement by $46 \%$ of respondents (27/59 centers). One center reported the use of magnetic resonance imaging (MRI) for intra-operative optimization of applicator placement.

Intra-cavitary brachytherapy was predominantly performed using tandem and ovoid $(80 \%, 47 / 59$ centers) and tandem ring (24\%, 14/59 centers) applicators. Complex applications (intracavitary with interstitial or interstitial alone, IC + IS/IS only) were being performed by $49 \%(29 / 59$ centers $)$ in $<10 \%$ of all cases and $15 \%$ ( $9 / 59$ centers) in $10-30 \%$ of all cases and by $5 \%(3 / 59$ centers) in more than $30 \%$ of cases. Some form of imaging was performed for planning by $97 \%$ (57/59 centers) of respondents, with CT scan $(65 \%, 38 / 59$ centers) and orthogonal X-rays $(36 \%, 21 / 59$ centers) being the most common modalities. MRI-based IGBT was performed by $9 \%$ ( $5 / 59$ centers). Point A based reporting remained the most commonly used form of method for dose volume reporting, with $66 \%$ (39/59 centers) using the same. Contemporary dose volume reporting, as mandated by the GEC-ESTRO guidelines [6,7], was performed by $36 \%$ (21/59 centers) of respondents. Seven percent (4/59 centers) of respondents reported using the 60 Gy reference isodose volume as stipulated by the ICRU-38 [8]. However, details of target volumes and dose constraints used for organs at risk were poorly reported and no analysis could be done for them. 
Table 1. Survey questions

\begin{tabular}{|c|c|c|c|}
\hline $\begin{array}{l}\text { Question } \\
\text { number }\end{array}$ & Question & Type of response & Options \\
\hline 1 & Kindly state your name & $\begin{array}{c}\text { Text reply } \\
\text { Single response allowed }\end{array}$ & NA \\
\hline 2 & $\begin{array}{c}\text { Kindly mention the name of the } \\
\text { institute where you are currently } \\
\text { working }\end{array}$ & $\begin{array}{l}\text { Text reply } \\
\text { Single response allowed }\end{array}$ & NA \\
\hline 3 & $\begin{array}{l}\text { Kindly state the nature of your } \\
\text { institute }\end{array}$ & $\begin{array}{l}\text { Check box } \\
\text { Single response allowed }\end{array}$ & $\begin{array}{l}\text { 1. Government Oncology Centre/Re- } \\
\text { gional Cancer Centre (RCC) } \\
\text { 2. Private Oncology Centre } \\
\text { 3. Medical College }\end{array}$ \\
\hline 4 & Kindly mark your area of expertise & $\begin{array}{l}\text { Check box } \\
\text { Single response allowed }\end{array}$ & Radiation oncologist \\
\hline 5 & $\begin{array}{l}\text { Kindly mention the extent of your } \\
\text { experience }\end{array}$ & $\begin{array}{l}\text { Check box } \\
\text { Single response allowed }\end{array}$ & $\begin{array}{l}\text { 1. } 1-5 \mathrm{yrs} \\
\text { 2. } 5-10 \mathrm{yrs} \\
\text { 3. } 10-15 \mathrm{yrs} \\
\text { 4. > } 15 \mathrm{yrs}\end{array}$ \\
\hline 6 & $\begin{array}{c}\text { What is the stage grouping of } \\
\text { cervical cancers that you see at your } \\
\text { institute? }\end{array}$ & $\begin{array}{c}\text { Table } \\
\text { Multiple responses allowed }\end{array}$ & $\begin{array}{l}\text { Categorically asked regarding num- } \\
\text { bers diagnosed per year and num- } \\
\text { bers treated per year as regards FIGO } \\
\text { stages: } \\
\text { IA-IB2 } \\
\text { IIA-IIB } \\
\text { IIIA-IIIB } \\
\text { IVA-IVB }\end{array}$ \\
\hline 7 & $\begin{array}{l}\text { Kindly specify the commonly used/ } \\
\text { institutional protocol for dose } \\
\text { fractionation schedules for external } \\
\text { beam radiotherapy (EBRT) and intra- } \\
\text { cavitary brachytherapy (ICBT) in your } \\
\text { institute in the table as indicated } \\
\text { (Please mention all doses in grays } \\
\text { in single digits, e.g. } 9 \text { Gy - please } \\
\text { enter as 9, if using decimals, please } \\
\text { restrict yourself to a single decimal, } \\
\text { e.g. } 7.5 \text { Gy) }\end{array}$ & $\begin{array}{c}\text { Table } \\
\text { Multiple responses allowed }\end{array}$ & $\begin{array}{l}\text { Asked under headings of } \\
\text { 1. Dose of EBRT(Gy) } \\
\text { 2. Mid-line shielding used(Yes/No) } \\
\text { 3. Midline shielding introduced at (Gy) } \\
\text { 4. No of sessions of ICBT } \\
\text { 5. Dose/session of ICBT(Gy) } \\
\text { Under stage groupings } \\
\text { 1. IA-IB2 } \\
\text { 2. IIA-IIB } \\
\text { 3. IIIA-IIIB }\end{array}$ \\
\hline 8 & $\begin{array}{l}\text { Please tick the methods for ICBT } \\
\text { used in your institute (Please feel } \\
\text { free to mark multiple options) }\end{array}$ & $\begin{array}{l}\text { Check box } \\
\text { Multiple responses allowed }\end{array}$ & $\begin{array}{l}\text { 1. Tandem ovoid type applicator } \\
\text { 2. Tandem ring type applicator } \\
\text { 3. Ring applicator with additional in- } \\
\text { terstitial needles (Vienna type) } \\
\text { 4. Tandem ovoid applicator with in- } \\
\text { terstitial needle grooves (Rotter- } \\
\text { dam type) } \\
\text { 5. Tandem/Ring ovoid applicator } \\
\text { with additional interstitial tem- } \\
\text { plates } \\
\text { 6. None of the above }\end{array}$ \\
\hline 9 & $\begin{array}{c}\text { In what percentage of cases of } \\
\text { advanced cervical cancer are you } \\
\text { performing complex interstitial } \\
\text { implants? }\end{array}$ & $\begin{array}{l}\text { Check box } \\
\text { Single response allowed }\end{array}$ & $\begin{array}{l}\text { 1. }<10 \% \\
\text { 2. } 10-30 \% \\
\text { 3. }>30 \%\end{array}$ \\
\hline 10 & $\begin{array}{c}\text { Kindly specify the method of pre- } \\
\text { scription for ICBT in your institute } \\
\text { (Please feel free to mark multiple } \\
\text { options) }\end{array}$ & $\begin{array}{c}\text { Check box } \\
\text { Multiple responses allowed }\end{array}$ & $\begin{array}{l}\text { 1. Point A based } \\
\text { 2. ICRU } 60 \text { Gy reference isodose } \\
\text { 3. Volume based prescription (GEC- } \\
\text { ESTRO) } \\
\text { 4. None of the above }\end{array}$ \\
\hline
\end{tabular}


Table 1. Cont.

\begin{tabular}{|c|c|c|c|}
\hline $\begin{array}{l}\text { Question } \\
\text { number }\end{array}$ & Question & Type of response & Options \\
\hline 11 & $\begin{array}{l}\text { How are you performing ICBT proce- } \\
\text { dures at your institute? (Please feel } \\
\text { free to mark multiple options) }\end{array}$ & $\begin{array}{c}\text { Check box } \\
\text { Multiple responses allowed }\end{array}$ & $\begin{array}{l}\text { 1. Sedation alone } \\
\text { 2. Sedation with local block } \\
\text { 3. Spinal anesthesia } \\
\text { 4. General anesthesia } \\
\text { 5. Local anesthesia } \\
\text { 6. None of the above }\end{array}$ \\
\hline 12 & $\begin{array}{l}\text { What sort of image guidance do you } \\
\text { use to rule out perforation and op- } \\
\text { timize applicator placement at your } \\
\text { institute? (Please feel free to mark } \\
\text { multiple options) }\end{array}$ & $\begin{array}{c}\text { Check box } \\
\text { Multiple responses allowed }\end{array}$ & $\begin{array}{l}\text { 1. USG } \\
\text { 2. CT } \\
\text { 3. MRI } \\
\text { 4. None of the above }\end{array}$ \\
\hline 13 & $\begin{array}{l}\text { What imaging modalities do you use } \\
\text { for planning ICBT in your practice? } \\
\text { (Please feel free to mark multiple } \\
\text { options) }\end{array}$ & $\begin{array}{c}\text { Check box } \\
\text { Multiple responses allowed }\end{array}$ & $\begin{array}{l}\text { 1. Orthogonal } X \text { rays } \\
\text { 2. USG } \\
\text { 3. CT } \\
\text { 4. MRI } \\
\text { 5. None of the above }\end{array}$ \\
\hline 14 & $\begin{array}{l}\text { What sort of optimization do you } \\
\text { use in ICBT planning? (please feel } \\
\text { free to mark multiple options) }\end{array}$ & $\begin{array}{c}\text { Check box } \\
\text { Multiple responses allowed }\end{array}$ & $\begin{array}{l}\text { 1. Manual dwell weights and times } \\
\text { 2. Geometrical optimisation } \\
\text { 3. Graphical optimisation } \\
\text { 4. Inverse optimisation (IPSA/HIPO) } \\
\text { 5. None of the above }\end{array}$ \\
\hline 15 & $\begin{array}{l}\text { Kindly specify the dose objectives } \\
\text { that you aim to achieve in day- } \\
\text { to-day planning of ICBT (Please } \\
\text { mention all doses in grays in single } \\
\text { digits, e.g. } 9 \text { Gy - please enter as 9, if } \\
\text { using decimals, please restrict your- } \\
\text { self to a single decimal, e.g. } 7.5 \text { Gy) }\end{array}$ & $\begin{array}{l}\text { Table with Check boxes } \\
\text { Multiple responses allowed }\end{array}$ & $\begin{array}{l}\text { Enquired about dose to } \\
\text { 1. Target (HR-CTV, IR-CTV, } 60 \text { Gy ref- } \\
\text { erence isodose) } \\
\text { 2. Bladder } \\
\text { 3. Rectum } \\
\text { 4. Sigmoid } \\
\text { In terms of the following parameters } \\
\text { 1. } 60 \text { Gy isodose volume } \\
\text { 2. HR CTV } \\
\text { 3. IR CTV } \\
\text { 4. Bladder } \\
\text { 5. Rectum } \\
\text { 6. Sigmoid }\end{array}$ \\
\hline 16 & $\begin{array}{c}\text { If you do not use 3D image based } \\
\text { brachytherapy at your institute, } \\
\text { when do you plan to institute the } \\
\text { same? }\end{array}$ & $\begin{array}{l}\text { Check box } \\
\text { Single response allowed }\end{array}$ & $\begin{array}{l}\text { 1. Within } 6 \text { months } \\
\text { 2. Within } 1 \text { year } \\
\text { 3. } 1-5 \text { yrs } \\
\text { 4. > } 5 \text { yrs } \\
\text { 5. No plans }\end{array}$ \\
\hline 17 & $\begin{array}{c}\text { What is the overall treatment time } \\
\text { that you typically achieve in the radi- } \\
\text { cal treatment of cervical cancer }\end{array}$ & $\begin{array}{l}\text { Check box } \\
\text { Single response allowed }\end{array}$ & $\begin{array}{l}\text { 1. }<42 \text { days } \\
\text { 2. } 42-49 \text { days } \\
\text { 3. }>49 \text { days } \\
\text { 4. } 49-56 \text { days } \\
\text { 5. }>56 \text { days }\end{array}$ \\
\hline
\end{tabular}

Plan optimization was performed by a variety of methods, with manual optimization of dwell weights and times being most common (52\%, 30/59 centers), followed by geometrical optimization $(44 \%, 26 / 59$ centers). Use of graphical optimization $(24 \%, 14 / 59$ centers) and inverse optimization $(12 \%, 7 / 59$ centers) remains lower.

Overall, $64 \%$ of respondents (38/59 centers) reported using some form of IGBT based on cross sectional imaging. In case of non-usage of IGBT, we enquired as to whether there were plans to implement IGBT in the near future, and the tentative time frames for implementing it. There were 24/59 responses; $7 \%$ (4/59 centers) replied that they had no plans for implementing IGBT at any time, $17 \%$ (10/59 centers) replied that they had plans to introduce IGBT in their clinical practice within the next 1-5 years. One respondent reported plans to implement IGBT within 1 year and 15\% (9/59 centers) reported that they had plans of commencing after more than 5 years. A comparison with other surveys is presented in Table 2. 
Table 2. Comparison of surveys

\begin{tabular}{|c|c|c|c|c|c|}
\hline Parameter & $\begin{array}{c}\text { ABS } 2010 \\
\text { Vishwanathan } \\
\text { et al. [17] }\end{array}$ & $\begin{array}{l}\text { ABS } 2016 \\
\text { Grover et al. [26] }\end{array}$ & $\begin{array}{l}\text { Canadian Survey } \\
2011 \\
\text { Pavamani et al. [16] }\end{array}$ & $\begin{array}{c}\text { Indian Survey } \\
\text { (AllMS) } \\
\text { Gandhi et al. } 2015 \\
{[15]}\end{array}$ & $\begin{array}{l}\text { Present Survey } \\
\text { (TMH) } \\
\text { Current study }\end{array}$ \\
\hline $\begin{array}{l}\text { No. of potential } \\
\text { participants/centers }\end{array}$ & 256 & 370 & 58 & 202 & 116 \\
\hline $\begin{array}{l}\text { No. of replies valid } \\
\text { for analysis }\end{array}$ & 133 & 219 & 36 & 90 & 59 \\
\hline $\begin{array}{l}\text { Response rate valid } \\
\text { for analysis }\end{array}$ & $51.9 \%$ & $59.1 \%$ & $62 \%$ & $44.5 \%$ & $50.8 \%$ \\
\hline $\begin{array}{l}\text { Academic centers } \\
\text { participating in the } \\
\text { survey }\end{array}$ & $30 \%$ & $46 \%$ & $100 \%$ & $72 \%$ & $54.2 \%$ \\
\hline Dose rate* & $\begin{array}{c}\text { HDR }-53 \% \\
\text { LDR }-15 \% \\
\text { Combination (HDR, } \\
\text { LDR and PDR alone } \\
\text { or in various combi- } \\
\text { nation) }-32 \%\end{array}$ & $\begin{array}{c}\text { HDR }-80 \% \\
\text { LDR }-3 \% \\
\text { Combination (HDR, } \\
\text { LDR and PDR alone } \\
\text { or in various combi- } \\
\text { nations) }-16 \%\end{array}$ & $\begin{array}{c}\text { HDR }-68 \% \\
\text { LDR }-24 \% \\
\text { PDR }-12 \% \\
\text { HDR and } \\
\text { LDR }-1.5 \% \\
\text { HDR or PDR }-3 \% \\
\end{array}$ & $\begin{array}{l}\text { HDR }-89 \% \\
\text { LDR }-13 \% \\
\text { PDR }-14 \%\end{array}$ & $\begin{array}{l}\text { HDR }-96.6 \% \\
L D R-2.5 \% \\
\text { PDR }-0.9 \%\end{array}$ \\
\hline $\begin{array}{l}\text { Imaging used } \\
\text { for insertion } \\
\text { and placement } \\
\text { optimization* }\end{array}$ & $\begin{array}{c}\text { USG }-56 \% \\
\text { Fluoroscopy }-37 \% \\
\text { CT }-24 \% \\
\text { None }-20 \% \\
\text { MRI - } 1 \text { center }\end{array}$ & $\begin{array}{c}\text { USG }-32 \% \\
\text { Fluoroscopy }-6 \% \\
\text { CT }-17 \% \\
\text { MRI }-4 \%\end{array}$ & USG - 35\% & No data & $\begin{array}{l}\text { USG }-28.8 \% \\
\text { CT - } 45.7 \% \\
\text { MRI - } 1 \text { centre }\end{array}$ \\
\hline $\begin{array}{l}\text { Imaging used for } \\
\text { planning* }\end{array}$ & $\begin{array}{c}\text { Orthogonal } \\
\text { X rays }-62 \% \\
C T-70 \% \\
M R I-2 \%\end{array}$ & $\begin{array}{c}\text { Orthogonal } \\
\text { X rays }-88 \% \\
\text { CT }-20 \% \\
M R I-34 \%\end{array}$ & $\begin{array}{c}\text { Orthogonal } \\
\text { X rays }-50 \% \\
\text { CT }-45 \% \\
M R I-5 \%\end{array}$ & $\begin{array}{c}\text { Orthogonal } \\
\text { X rays }-56 \% \\
C T-69 \% \\
M R I-14 \%\end{array}$ & $\begin{array}{c}\text { Orthogonal } \\
\text { X rays }-35.6 \% \\
\text { CT }-64.4 \% \\
\text { MRI }-8.5 \%\end{array}$ \\
\hline $\begin{array}{l}\text { Method for dose } \\
\text { volume reporting for } \\
\text { target* }^{*}\end{array}$ & $\begin{array}{c}\text { Point A }-76 \% \\
3 \mathrm{D}(\mathrm{CTV} \text { based })- \\
14 \% \\
\text { Both point A and } \\
\text { CTV based }-7 \% \\
\text { Point A and } \mathrm{mg} / \mathrm{h} \\
-3 \%\end{array}$ & $\begin{array}{c}\text { Point A }-46 \% \\
\text { GEC-ESTRO } \\
(\text { HR-CTV })-52 \%\end{array}$ & $\begin{array}{c}\text { MRI users } \\
\text { GEC-ESTRO - } 100 \% \\
\text { CT/MRI users } \\
\text { Point A - } 50 \% \\
\text { GEC-ESTRO }-44 \%\end{array}$ & No data & $\begin{array}{c}\text { Point A }-66.1 \% \\
\text { ICRU } 3860 \text { Gy refer- } \\
\text { ence isodose }-7 \% \\
\text { GEC-ESTRO }-35.9 \%\end{array}$ \\
\hline
\end{tabular}

*indicates percentages may add up to more than 100, HDR - high-dose-rate, LDR - low-dose-rate, PDR - pulsed-dose-rate

\section{Discussion}

Radiation therapy including brachytherapy forms an indispensable part of the curative management of LACC [9]. Even in FIGO stage IIIB-IVA, local control outside the setting of a clinical trial can be as high as $85 \%$ [10], which is unprecedented in locally advanced squamous carcinomas originating at other sites. However, there are several challenges in achieving this, especially in LMICs, including India, in terms of resources, logistics and expertise. For example, there is shortage of radiation therapy units, skilled human resources [11], and EBRT and brachytherapy units required for timely ICBT and execution of optimal standard treatment protocols $[12,13]$. We undertook this survey with an aim to understand the gaps in radiotherapeutic management of cervical cancers and to capture details related to radiation therapy for cervical cancer in India. An additional important objective was to understand the acceptance and uptake of newer technologies in brachytherapy in the light of emerging evidence on improved outcomes with image-guided brachytherapy in routine clinical practice [14].

Our survey attained a response rate of $51 \%$, which was higher than a recent survey conducted in an LMIC [15] setting, but lower than those in an non-LMIC setting $[16,17]$. The majority of our respondents were from academic institutes with a single response from each institution rather than individual physicians. Also, all the respondents in our study are radiation oncologists and experienced in treating a relatively large number of cervical cancer patients annually (median 161 patients). This is an important and somewhat reassuring finding as treatment at academic and high volume centers has been shown to be associated with better outcomes in cervical cancer $[18,19,20]$.

All the respondents reported a near uniform EBRT treatment protocol of 45-50 Gy followed by ICBT schedules most commonly prescribing 7 Gy $\times 3-4$ fractions, mirroring earlier reported practice in India [21]. Also, the overwhelming majority reported using HDR brachyther- 
apy $(97 \%)$, which is reflective of changing global practice [22] and $>90 \%$ completing the treatment within 56 days and $10 \%$ exceeding the overall treatment time (OTT). The exceeded OTT is highly likely to directly impact patient outcomes, and probably arises out of a large unmet need for more EBRT and brachytherapy units which has been found to be substantial and accordingly deserves attention [13]. Approximately two thirds (62\%) perform ICBT after completion of EBRT, which is in line with contemporary global practice [23]. The applicator insertion procedure is usually done under some form of anesthesia. Brachytherapy application is a relatively painful procedure involving pelvic examination, negotiating the utero-cervical canal, cervical canal dilatation and placement of applicators in the upper vagina followed by vaginal packing. To mitigate the resultant pain and discomfort, the brachytherapy procedure is usually done under anesthesia and analgesic cover. Our survey results suggest that the majority of centers perform the brachytherapy procedure under some form of anesthesia, which is encouraging and will likely translate into appropriate placement.

Asymptomatic perforation is a known entity during ICBT, which may not be picked up on routine imaging. As many as $13.7 \%$ of insertions, including $8.7 \%$ of insertions where the treating radiation oncologist was confident regarding correct tandem placement, were found to harbor perforations on CT imaging [24]. To minimize the uterine perforation rates use of real-time ultrasonography during the procedure is attractive and implemented in clinical practice [25]. In our survey, $29 \%$ of respondents used USG guidance and $46 \%$ of respondents performed CT imaging for optimizing applicator insertion and placement, suggesting some QA for optimizing BT insertions. Advanced BT applications including IC + IS were performed in approximately $30 \%$ of cases by only 3 centers $(5 \%)$ in a setting where locally advanced cervical cancer is seen in more than $2 / 3$ in routine clinical practice. This may be attributed to lack of: (i) advanced BT applicators and (ii) availability of expertise and skills.

Almost all of the respondents (97\%) reported use of imaging for brachytherapy planning. Also, the rates of usage of orthogonal X-rays (36\%) are lower than previously reported from India [12] and data from North America published 5-8 years ago [17], while CT imaging was used by two thirds, which is relatively few as compared to other series [26]. The use of MR imaging has improved from $2 \%$ to $8 \%$ since 2007 but is substantially lower than the western reports [26]. A comparative table between the current survey and similar surveys conducted in the West illustrates these differences in greater detail (Table 2).

Despite the relatively good availability and uptake of cross sectional imaging, especially CT, point A based dose prescription remained the most common form of prescription. The ICRU-38 60 Gy reference isodose volume reporting was negligible, reflecting lower acceptability, similar to published literature [27]. Use of GECESTRO volume-based parameters was performed by $36 \%$ of respondents, similar to other reported series [26]. This suggests that point A prescription is still a preferred method, with approximately one third of respondents using it during the transition from $2 \mathrm{D}$ to $3 \mathrm{D}$ based parameters.
Although MRI-based dose volume parameters are the gold standard, the major hurdle in the Indian setting is lack of MRI in radiation oncology departments and limited access to MRI in the radiology clinic due to competing indications and long queues. This is also reflected in our survey, with extremely poor reporting of target and organ at risk (OAR) related dose volume parameters and limited optimization utilization even for routine ICBT applications. To mitigate this, there have been attempts for alternatives. A recent publication by Mahantshetty et al. showed that using intraoperative trans-rectal ultrasonography (TRUS) and peri-operative CT combined with image information from MRI at diagnosis would lead to target and OAR delineation which was just as robust as gold-standard MRI-based image-based brachytherapy (IBBT) [28]. Such attractive alternatives would be more beneficial and will be better utilized in Indian and LMIC settings.

Finally, in terms of implementation plans in the near future, approximately one third of the respondents wish to introduce some form of image-based brachytherapy within the next 5 years. The results of a survey conducted 4 years ago amongst participants of an IBS conference identified training as the main hurdle towards practicing brachytherapy and showed resolve towards changing practice patterns after the conference [15]. This seems to be reflected in the increased uptake of imaging, especially cross sectional imaging in ICBT planning in the results of our survey. The increased resolve of stakeholders in conjunction with the ongoing efforts of various national (AROI, IBS) and international organizations (ESTRO) for dissemination and implementation of IGBT in cervical cancers seems to be reaping rewards. Also, various strategies to motivate economically viable solutions are being reported for increasing viability for potential stakeholders, e.g. a health economic model for MRI-based IGABT approach [29] and alternative imaging protocols including ultrasonography/CT hybrid combinations [28]. We believe these efforts will be highly fruitful in due course.

Our survey report has some limitations including relatively low participation rates, inherent bias in terms of responses from possibly motivated institutions/centers, and no detailed questions on the quality indicators of EBRT techniques and chemotherapy. Despite these limitations, the current publication represents patterns of care in cervical cancer as practiced among experienced clinicians with a high caseload in an LMIC setting and is likely to offer useful insights into improving outcomes in cervical cancer in many other similar settings.

\section{Conclusions}

Our survey results suggest a fairly uniform pattern of radiotherapy treatment for cervical cancer, with EBRT doses of 45-50 Gy and 3-4 fractions of high dose rate ICBT of $7 \mathrm{~Gy}$ each with reasonable overall treatment times. There is an increasing trend for use of cross sectional imaging, particularly CT imaging for BT planning with point A prescription/reporting only, while target concept and volume based prescription is still in transition. Finally, the intentions to implement 3D IGBT for cervical can- 
cer are increasing. A follow-up survey after a few years and comparison with the results of the current survey would be useful to evaluate transition/changing practices in brachytherapy for cervical cancers.

\section{Acknowledgements}

The survey was selected for poster presentation at the American Brachytherapy Society (ABS) 2018 conference.

\section{Disclosure}

The authors report no conflict of interest.

\section{References}

1. Ferlay J, Soerjomataram I, Dikshit R et al. Cancer incidence and mortality worldwide: sources, methods and major patterns in GLOBOCAN 2012. Int J Cancer 2015; 136: E359-386.

2. Shrivastava. Treatment and outcome in cancer cervix patients treated between 1979 and 1994: A single institutional experience. Available at http://www.cancerjournal.net $/$ article. asp?issn=0973-1482; year=2013; volume $=9 ;$ issue $=4 ;$ spage $=672 ;$ epage $=679 ;$ aulast $=$ Shrivastava . Accessed: June 23, 2018.

3. Shrivastava S, Mahantshetty U, Engineer R et al. Cisplatin chemoradiotherapy vs radiotherapy in FIGO stage IIIB squamous cell carcinoma of the uterine cervix: a randomized clinical trial. JAMA Oncol 2018; 4: 506-513.

4. Indian Brachytherapy Society. Available at http://www.indianbrachytherapy.org/. Accessed: August 25, 2019.

5. Mahantshetty U, Gudi S, Singh R et al. Indian Brachytherapy Society Guidelines for radiotherapeutic management of cervical cancer with special emphasis on high-dose-rate brachytherapy. J Contemp Brachytherapy 2019; 11: 293-306.

6. Pötter R, Haie-Meder C, Van Limbergen E et al. Recommendations from gynaecological (GYN) GEC ESTRO working group (II): concepts and terms in 3D image-based treatment planning in cervix cancer brachytherapy-3D dose volume parameters and aspects of 3D image-based anatomy, radiation physics, radiobiology. Radiother Oncol 2006; 78: 67-77.

7. Haie-Meder C, Pötter R, Van Limbergen E et al. Recommendations from Gynaecological (GYN) GEC-ESTRO Working Group (I): concepts and terms in 3D image based 3D treatment planning in cervix cancer brachytherapy with emphasis on MRI assessment of GTV and CTV. Radiother Oncol 2005 74: $235-245$

8. International Commission on Radiation Units and Measurements (ICRU). Available at https://icru.org/home/ reports/dose-and-volume-specification-for-reporting-intracavitary-therapy-in-gynecology-report-38. Accessed June 23, 2018.

9. Shrivastava SK, Lewis S, Sastri SC et al. Cancer cervix: Establishing an evidence-based strategy, an experience of a tertiary care centre in India. Curr Probl Cancer 2018; 42: 137-147.

10. Mittal P, Chopra S, Pant S et al. Standard chemoradiation and conventional brachytherapy for locally advanced cervical cancer: is it still applicable in the era of magnetic resonance-based brachytherapy? J Glob Oncol 2018; 4: 1-9.

11. Datta NR, Samiei M, Bodis S. Radiation therapy infrastructure and human resources in low- and middle-income countries: present status and projections for 2020. Int J Radiat Oncol Biol Phys 2014; 89: 448-457.

12. Nandakumar A, Kishor Rath G, Chandra Kataki A et al. Concurrent chemoradiation for cancer of the cervix: results of a multi-institutional study from the setting of a developing country (India). J Glob Oncol 2015; 1: 11-22.
13. Chopra S, Shukla R, Budukh A, Shrivastava SK. External radiation and brachytherapy resource deficit for cervical cancer in India: call to action for treatment of all. J Glob Oncol 2019; 5: $1-5$.

14. Derks K, Steenhuijsen JLG, van den Berg HA et al. Impact of brachytherapy technique (2D versus $3 \mathrm{D}$ ) on outcome following radiotherapy of cervical cancer. J Contemp Brachytherapy 2018; 10: 17-25.

15. Gandhi AK, Sharma DN, Julka PK, Rath GK. Attitude and practice of brachytherapy in India: a study based on the survey amongst attendees of Annual Meeting of Indian Brachytherapy Society. J Contemp Brachytherapy 2015; 7: 462-468.

16. Pavamani S, D'Souza DP, Portelance L et al. Image-guided brachytherapy for cervical cancer: a Canadian Brachytherapy Group survey. Brachytherapy 2011; 10: 345-351.

17. Viswanathan AN, Erickson BA. Three-dimensional imaging in gynecologic brachytherapy: a survey of the American Brachytherapy Society. Int J Radiat Oncol Biol Phys 2010; 76: 104-109.

18. Lee MS, Tsai SJ, Lee CC et al. Higher caseload improves cervical cancer survival in patients treated with brachytherapy. Radiat Oncol 2014; 9: 234.

19. Lin JF, Berger JL, Krivak TC et al. Impact of facility volume on therapy and survival for locally advanced cervical cancer. Gynecol Oncol 2014; 132: 416-422.

20. Wright JD, Huang Y, Ananth CV et al. Influence of treatment center and hospital volume on survival for locally advanced cervical cancer. Gynecol Oncol 2015; 139: 506-512.

21. Bandyopadhyay A, Basu P, Roy K et al. Treatment of locally advanced carcinoma cervix with special emphasis on brachytherapy: A practice pattern survey among young radiation oncologist of India. South Asian J Cancer 2018; 7: 231-235.

22. Marchant KJ, Sadikov E. The evolving practice of intrauterine cervix brachytherapy in Canada: a medical physics perspective. Brachytherapy 2013; 12: 324-330.

23. Dimopoulos JCA, Schirl G, Baldinger A et al. MRI assessment of cervical cancer for adaptive radiotherapy. Strahlenther Onkol 2009; 185: 282-287.

24. Barnes EA, Thomas G, Ackerman I et al. Prospective comparison of clinical and computed tomography assessment in detecting uterine perforation with intracavitary brachytherapy for carcinoma of the cervix. Int J Gynecol Cancer 2007; 17: 821-826.

25. Davidson MTM, Yuen J, D'Souza DP et al. Optimization of high-dose-rate cervix brachytherapy applicator placement: the benefits of intraoperative ultrasound guidance. Brachytherapy 2008; 7: 248-253.

26. Grover S, Harkenrider MM, Cho LP et al. Image Guided Cervical Brachytherapy: 2014 Survey of the American Brachytherapy Society. Int J Radiat Oncol Biol Phys 2016; 94: 598-604.

27. Pötter R, Van Limbergen E, Gerstner N, Wambersie A. Survey of the use of the ICRU 38 in recording and reporting cervical cancer brachytherapy. Radiother Oncol 2001; 58: 11-18.

28. Mahantshetty U, Naga Ch P, Khadanga CR et al. A prospective comparison of computerized-tomography (CT) based with trans-rectal-ultrasonography (TRUS) assistance and magnetic-resonance imaging (MRI) based target-volume definition during image guided adaptive brachytherapy for cervical cancers. Int J Radiat Oncol Biol Phys 2018; 102: 1448-1456.

29. Chakraborty S, Mahantshetty U, Chopra S et al. Income generated by women treated with magnetic resonance imaging-based brachytherapy: A simulation study evaluating the macroeconomic benefits of implementing a high-end technology in a public sector healthcare setting. Brachytherapy 2017; 16: 981-987. 